\title{
Computer-Aided English Teaching Platform Based on Secure Shell Framework
}

\author{
https://doi.org/10.3991/ijet.v14i16.11149 \\ Lingling Qiu \\ Guizhou University of Finance and Economics, Guiyang, China \\ 64443939 @qq. com
}

\begin{abstract}
With the aid of information-based teaching platform, the traditional classroom English teaching mode can be improved to provide students with a realistic linguistic environment and enhance their learning interest. As a result, the web-based computer aided English teaching has become the mainstream in college English education. Based on the browser/server $(\mathrm{B} / \mathrm{S})$ structure, this paper designs a computer-aided English teaching platform of the model-view-controller (MVC) architectural pattern. The programming was carried out using the MySQL database, and the functions of the computer-aided English teaching platform were realized securely and stably by the popular Secure Shell (SSH) framework. The system test results show that the proposed platform supports the open teaching of college English, solves the lack of interaction in traditional classroom teaching, and arouses the students' learning interest. The research further promotes the reform of college English teaching, and enriches the theories and practices on computer-aided English teaching.
\end{abstract}

Keywords - Secure shell (SSH), English teaching, computer aided teaching system

\section{Introduction}

The continuous popularization of information technology and Internet technology has greatly promoted the process of education informatization in China. At present, colleges and universities across the country have basically achieved $100 \%$ coverage of computers. With the aid of computer network technology, the key and difficult knowledge points can be conveyed to students with vivid sounds or images [1], thus making the teaching work easier to develop. So, it has become the research focus of educational experts at all levels and software development enterprises on how to integrate various types of computer network teaching resources into English teaching work and improve students' interest in learning.

The application of computers in the field of teaching began in the 1960s. By the 1970s and 1980s, a large number of computer-assisted learning systems had come into being, of which PLATO was more famous [2]. The computer-aided language learning system can change the traditional cramming teaching, build a real language 
learning environment for students to learn English in a variety of ways, improve students' interest in learning, help them to form a positive learning attitude, and highlight their dominant role in the classroom [3], so it has developed rapidly in recent years.

Mark Warschauer [4] emphasizes that computer-aided language learning is conductive to familiarizing with the language learning environment and mastering language learning skills. Xu Dongmin et al. proposed a network-based hierarchical teaching model. Andi Tenri Ampa [5] conducted research on learning media and student learning effects of listening. In addition, for the computer-aided English teaching system based on B/S structure, .NET technology, Java technology, object-oriented technology and Web-based technology, abundant research achievements have been made by some domestic and foreign scholars [6], However, the in-depth research and analysis find that in the current computer-aided English teaching network system of China, there still exist the problems such as independent existence of system, no evolvability, poor expansion, slow response, untimely update, lack of effective links between functional modules, and insufficient construction of online learning environment [7].

Based on the above analysis, in order to solve the problems existing in the current College English teaching, this paper adopts object-oriented technology to acquire the main functional requirements of the English teaching platform. Then, it gives a brief description of related technologies. Among them, the SSH framework technology was used to design and implement the computer-aided English teaching platform in detail.

\section{System Related Technology}

\subsection{SSH framework}

SSH [8] is a Java web application-based open source framework consisting of Struts+Spring+Hibernate. Spring is to manage Struts and Hibernate, responsible for business management layer; Struts is the overall architecture of system, responsible for the Web layer, and its MVC design pattern can ensure the clear logic clear and structure [9]; Hibernate provides a fully object-oriented database operation to complete the data persistence, and it is responsible for the data persistence layer; DAO is the po, hbm.xml file corresponding to the database table in Hibernate [10]. Fig 1 shows the SSH architecture diagram. 


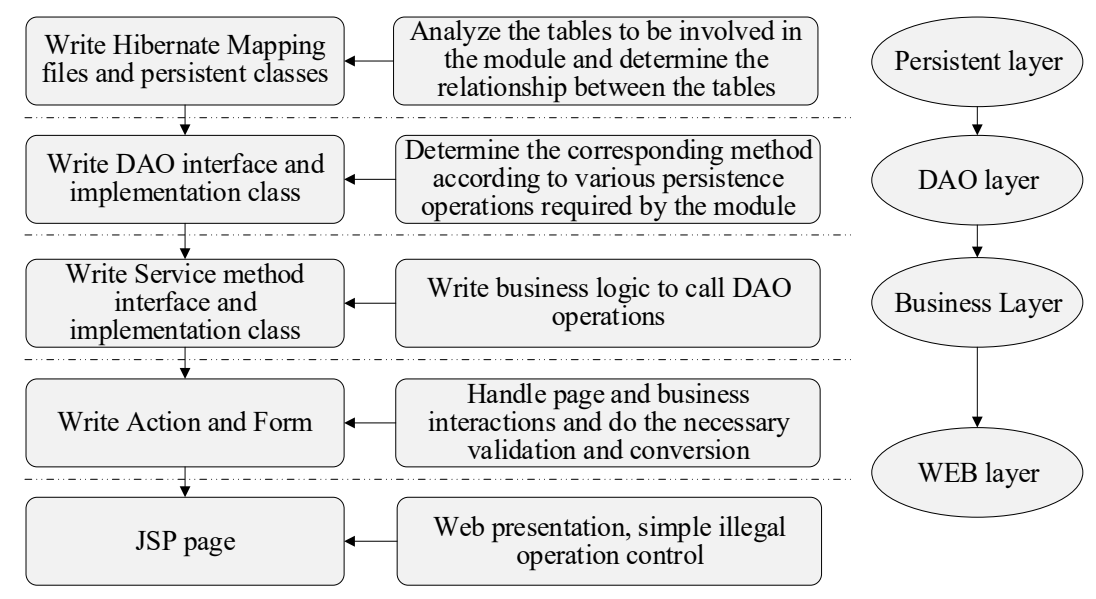

Fig. 1. SSH architecture diagram

\subsection{MVC design pattern}

MVC [11] is the abbreviation of Model View Controller, where Model is the data model, for the business logic layer of the application; View is the interface, providing the mechanism for collecting data from the user, and visualizing the data; Controller can receive and briefly process the user data, and feed the processing result back to the data model. MVC is a design pattern that can simplify application development and maintenance by separating data, business logic and interface display [12]. Fig 2 shows a schematic diagram of $\mathrm{SSH}+\mathrm{MVC}+$ layered architecture.

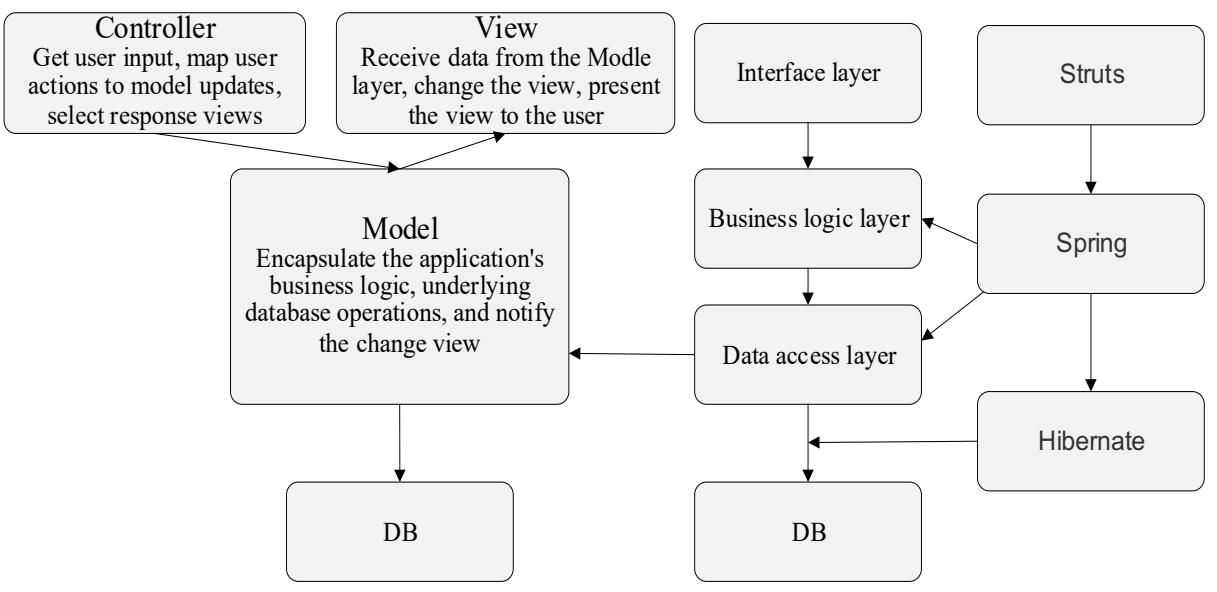

Fig. 2. $\mathrm{SSH}+\mathrm{MVC}+$ layered architecture diagram 


\subsection{MySQL database}

MySQL database can support most of the open source operating system, and be installed in the Windows operating system by a variety of ways. It also has the advantages such as small size, fast speed, high performance, low cost, and a good accessing function to data interface [13]. All these make the MySQL database the first choice for building a networked teaching system.

\section{Design and Application of Computer-Aided English Teaching Platform Based on SSH Framework}

\subsection{System function requirements analysis}

To ensure that the designed computer-aided teaching platform meets the needs of college English teaching, this paper analyses the functions of the system from the perspective of the system user. The computer-aided English teaching platform should first meet the teachers' needs of virtual teaching and classroom teaching as well as related teaching resource management needs. Then, it should satisfy the students' needs based on English situational learning and the need of teacher-student interaction discussion. According to the above analysis, the system requirements can be divided into six functions: system information management, traditional English teaching operation management, interactive communication discussion, teacher virtual teaching, English learning situation teaching and learning evaluation, and management of teaching system resources and data, as shown in Fig 3.

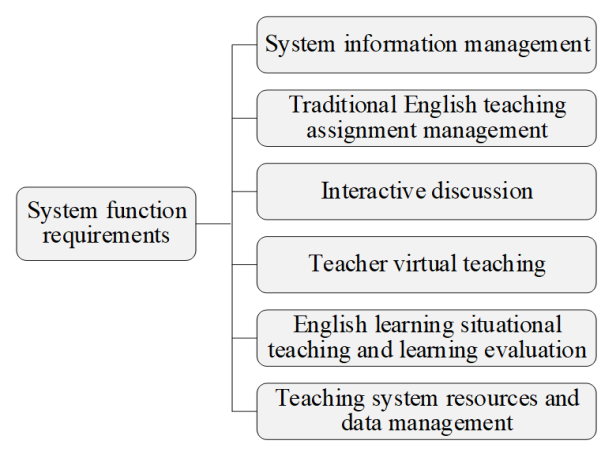

Fig. 3. System function requirements

\subsection{System module division}

Based on the analysis of system function requirements, this paper divides the computer-aided English teaching system into three modules: system login module, teacher teaching and student learning module, system management and maintenance. The specific module functions are shown in Fig 4. 


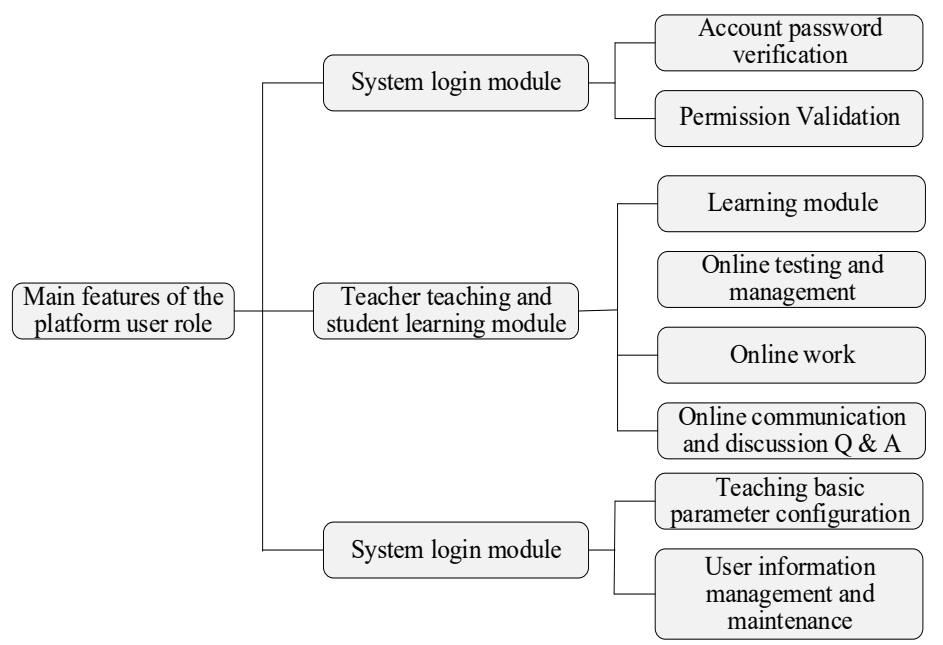

Fig. 4. Functional Map of Computer English Aided Teaching System in Colleges and Universities

System login module: The system login module is mainly to ensure the system security, and the users with different permissions will log in to different system interfaces. It includes account password verification and permission verification.

Teacher teaching and student learning module: The teacher teaching and student learning module is the core to realize the system function, including the following main functions:

Learning module: According to the syllabus, curriculum design and academic analysis, the teacher uploads the audio, video and text materials of the teaching resources for students to study in class and after class, or delete and modify related resources; students can search and browse related content according to the requirements, or download related resources.

Online assignment: Students can upload assignments arranged by teachers in the file form, or they can complete these assignments online.

Online communication and discussion $\mathbf{Q} \& \mathbf{A}$ : It is divided into two parts; one part can provide classroom and online interactive communication for teachers and students, and the other can facilitate students to leave a message on the message board in case of problems after class, and make discussions between teachers and students or between students.

Online testing and management: Teachers can use the module to conduct in-class assessments, and students can also make self-test after class. The system will automatically review the test papers and analyse the student scores, both the teachers and students can view the historical analysis and ranking of test scores so as to help them understand the learning outcomes.

System management and maintenance module: This module contains two parts: the basic parameters configuration of the system (operation log, the system interface settings etc.), and the information management and maintenance of users (teachers, students, and permissions). 


\subsection{Implementation of system main function modules}

System login module: Users (teachers, students, administrators) need to enter their personal username and password on the system interface before logging in to the system, and users with different permissions have different interfaces to enter the system. As a result, the system uses sturts.xml is used to determine the correctness of the input password by the user, and the cookie is to determine whether the user successfully logged in; if the password or user name is entered incorrectly, the user shall not enter the corresponding interface; if no operation is performed after logging on for a certain period of time, the user needs to log in again, Fig 5 shows the user login interface system.

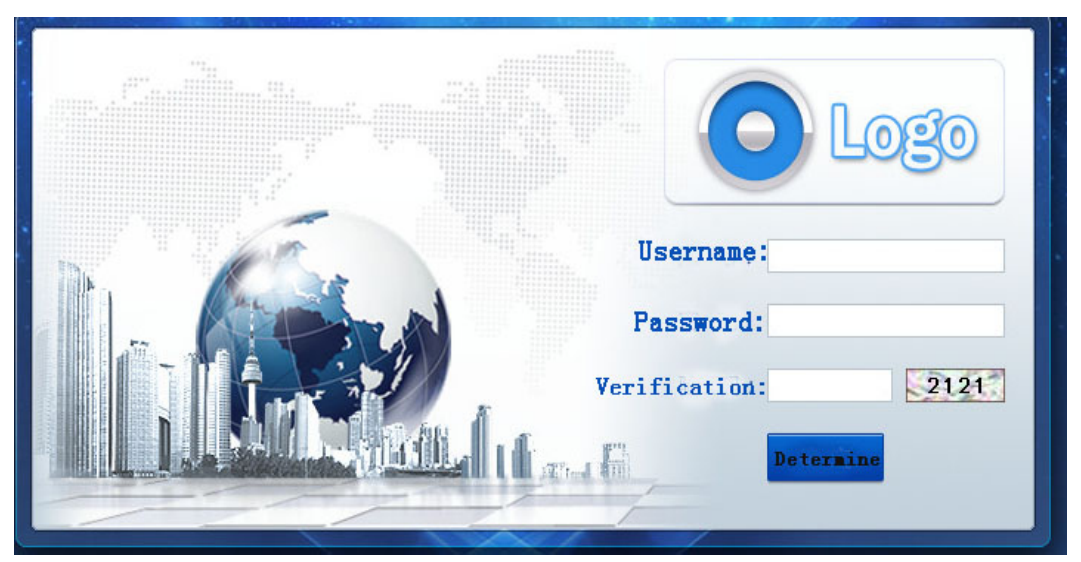

Fig. 5. System login interface

\section{Teacher teaching and student learning module}

Learning module: Students in the learning module can view the course learning content arranged by the teacher, the teacher's comments on their homework, tests and related test scores, and they can click on the link to enter the relevant links. The system also automatically records the student's learning record and study time, so that the teacher can track the student's learning status. In addition, the learning module can provide knowledge point query function, which is convenient for students to query relevant knowledge according to their own needs for learning, e.g., students can input relevant knowledge point names in the search field of knowledge point, and then filter the related information such as learning videos, texts, and images. Fig 6 shows the search interface of knowledge point. 


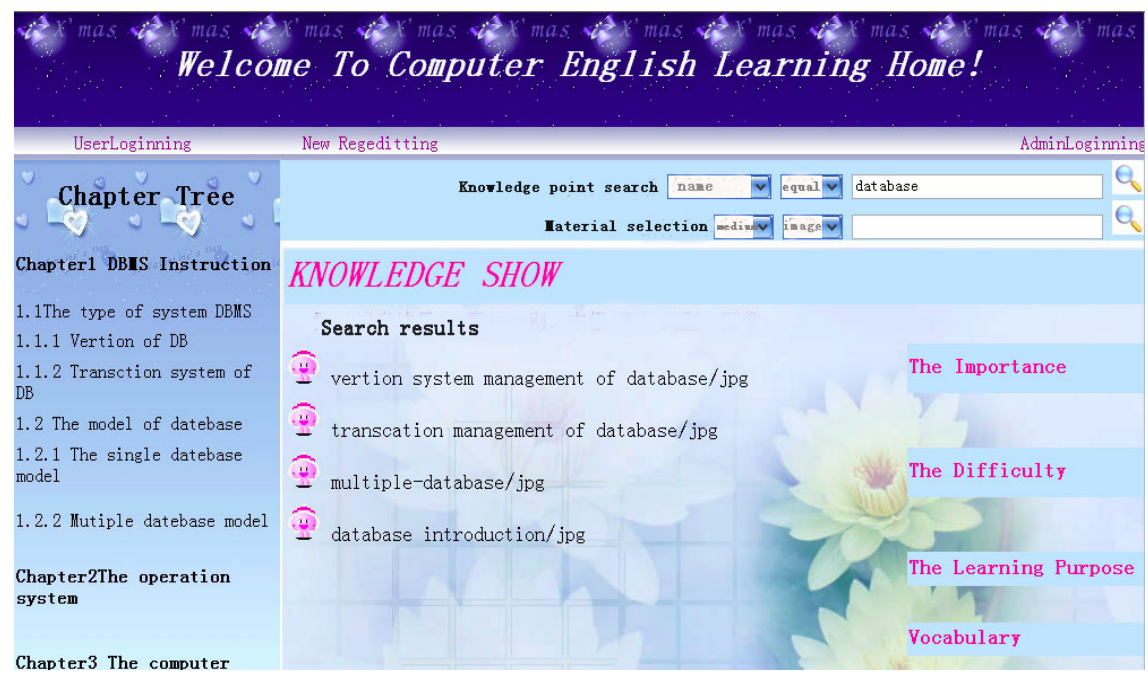

Fig. 6. Chapter knowledge point search interface

Online assignment: Through the online assignment module, the students' homework is not limited to English writing, cloze test and reading comprehension; the teachers can also use the relevant video and audio resources to comprehensively examine the students' listening and reading comprehension skills, and review their homework online; students can choose to do homework online, or download relevant resources, and upload the completed homework to the system; the uploaded content can include resources in various formats such as video, audio, text, etc.; students can view teacher's comments online. Fig 7 shows the student assignment interface.

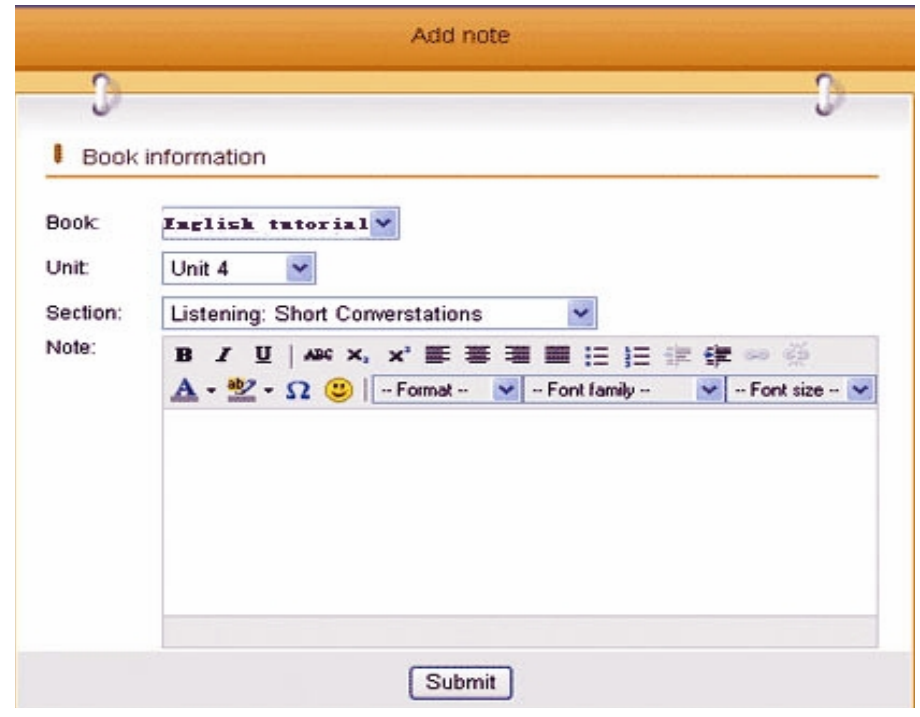

Fig. 7. Student assignment page 


\subsection{System function test and application effect evaluation}

System function test: After the design of computer-aided teaching system was completed, the software and various functional modules of the system were tested. The test results show that except for small defects with the message function and upload function, the others meet the functional requirements and achieve the expected design goals. In addition, when it's simulated for 100 to 1,000 users accessing the system at the same time, although the system CPU has significantly increased, it still remains at about $40 \%$. Therefore, the designed system passes the test.

System application effect evaluation: In order to verify the designed computeraided English teaching system, this paper selects a class (45 students) of college English as the experimental subject, and adopts this teaching system. After one semester, a comparative analysis before and after the experiment was conducted about the academic performance and attitude.

Comparative analysis of academic performance before and after the experiment: Fig 8 compares the academic performance of experimental class in the computerassisted English teaching method and the traditional teaching method. It can be seen from the figure that after using the computer-assisted English teaching method, the scores of various test items have increased, especially, the scores of listening and written expressions are the most significant, and the total score of students have increased from 76.4 to 90.1 , indicating that computer-assisted teaching can effectively improve the English teaching.

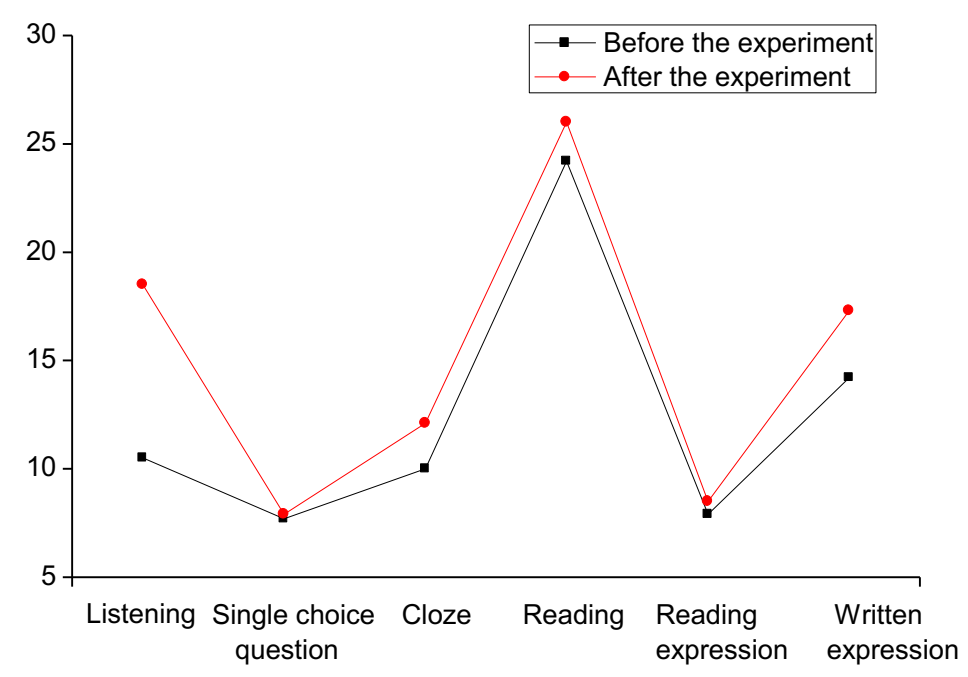

Fig. 8. Academic performance before and after the experiment

Comparative analysis of students' attitude towards English learning in experimental class: Fig 9 and 10 show the students' attitudes towards English learning before and after the experiment in the experimental class. It can be seen from the figure that the students' attitude towards English has changed greatly after the experiment; 
only $4 \%$ students after the experiment said that they disliked to learn English; the number of students who liked very much and liked English learning increased from $53 \%$ to $73 \%$, indicating that the computer-assisted English teaching method can stimulate students' interest in learning and enhance their enthusiasm for learning.

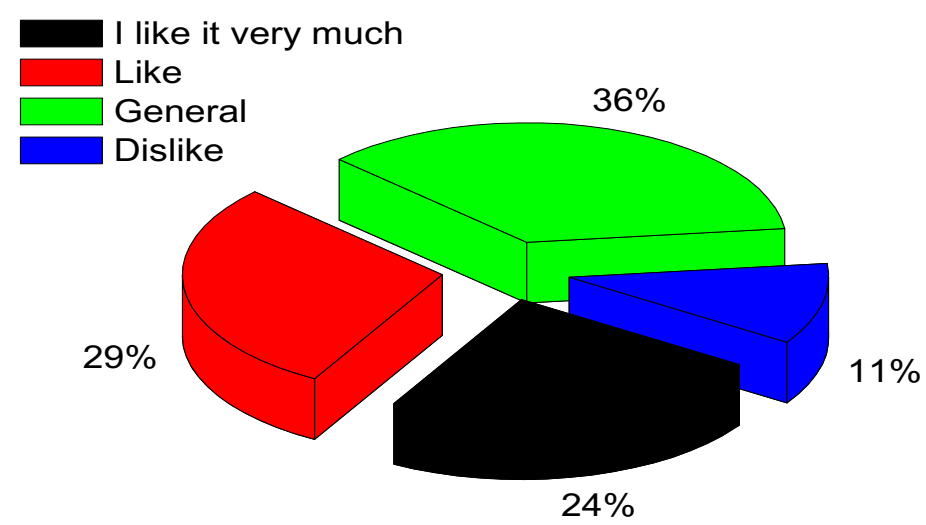

Fig. 9. Attitude towards English before the experiment

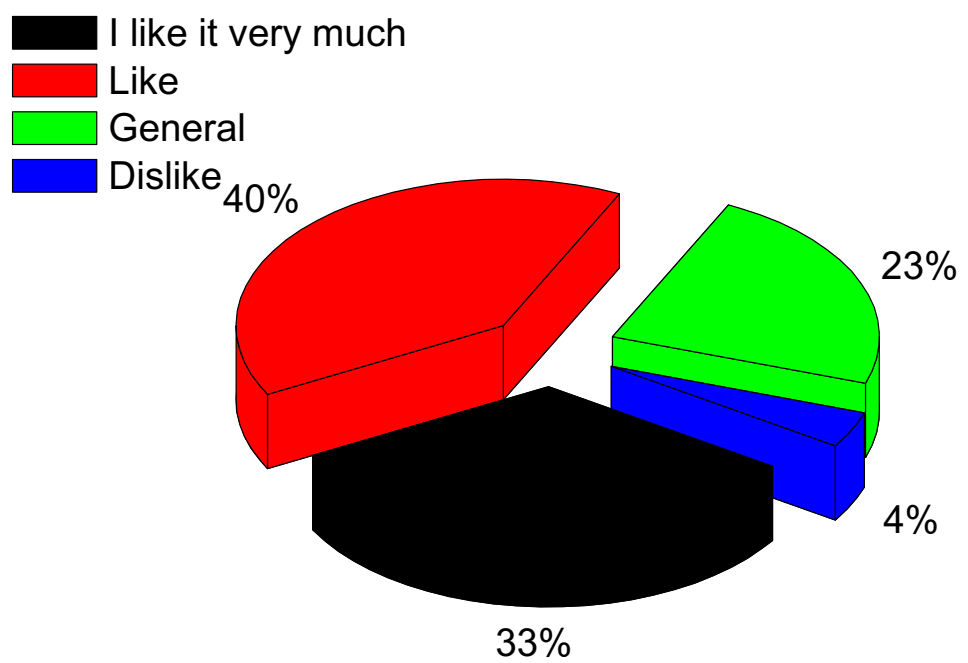

Fig. 10.Attitude towards English after the experiment

\section{Conclusion}

This paper studies the computer-assisted English teaching platform under the network environment. The specific conclusions are as follows: 
- From the perspective of the system user, it analyses the functions of the system, and classifies the functional modules of the system and their tasks in detail.

- Based on the browser/server (B/S) structure, the computer-aided English teaching platform was designed of the model-view-controller (MVC) architectural pattern and programmed by the MySQL database; the popular Secure Shell (SSH) framework was used to design and implement all system modules in detail.

- The system test results show that the platform is stable and can meet the needs of computer-assisted English teaching. It also helps to stimulate students' interest in learning and improve teaching effects.

\section{$5 \quad$ References}

[1] Jarvis, H. (2010). Issues of computer-mediated communication for English language teaching. British Journal of Educational Technology, 37(4): 643-645. https://doi.org/ $10.1111 / \mathrm{j} .1467-8535.2006 .00592 . x$

[2] Kilıçkaya, F. (2009). The effect of a computer-assisted language learning course on preservice english teachers' practice teaching. Educational Studies, 35(4): 437-448. https://doi.org/10.1080/03055690902876545

[3] Boyd, G., Keller, A., Kenner, R. (1982). Remedial and second language english teaching using computer assisted learning. Computers \& Education, 6(1): 105-112. http://dx.doi. org/10.1016/b978-0-08-028111-7.50020-9. https://doi.org/10.1016/0360-1315(82)90019-7

[4] Özyurt, Ö., Özyurt, H., Baki, A. (2013). Design and development of an innovative individualized adaptive and intelligent e-learning system for teaching-learning of probability unit: details of uzwebmat. Expert Systems with Applications, 40(8): 29142940. https://doi.org/10.1016/j.eswa.2012.12.008

[5] Ye, Z., Hua, C. (2012). An innovative method of teaching electronic system design with psoc. IEEE Transactions on Education, 55(3): 418-424. https://doi.org/10.1109/te.2011. 2181994

[6] Souza, R. P., Pinheiro, T., Magalhaes, A. L. C. C., Mesquita, R. C. (1998). An objectoriented platform for teaching finite element pre-processor programming and design techniques. IEEE Transactions on Magnetics, 34(5): 3407-3410. https://doi.org/10.1109/ 20.717802

[7] Li, X. (2018). Influence of computer-aided instruction model on business english writing teaching effect, International Journal of Emerging Technologies in Learning, 13(3): 197206. https://doi.org/10.3991/ijet.v13i03.8396

[8] Boyd, G., Keller, A., Kenner, R. (1982). Remedial and second language english teaching using computer assisted learning. Computers \& Education, 6(1): 105-112. http://dx.doi. org/10.1016/b978-0-08-028111-7.50020-9. https://doi.org/10.1016/0360-1315(82)90019-7

[9] Edwards, M. J., Aldous, I. R. (2010). Attitudes to and knowledge about elderly people: a comparative analysis of students of medicine, english and computer science and their teachers. Medical Education, 30(3): 221-225. https://doi.org/10.1111/j.13652923.1996. tb00746.x

[10] Lan, Y. J., Sung, Y. T., Chang, K. E. (2009). Let us read together: development and evaluation of a computer-assisted reciprocal early english reading system. Computers \& Education, 53(4): 1188-1198. https://doi.org/10.1016/j.compedu.2009.06.002

[11] Jia, J. (2009). Csiec: a computer assisted english learning chatbot based on textual knowledge and https://doi.org/10.1016/j.knosys.2008.09.001reasoning. Knowledge-Based Systems, 22 (4): 249-255. https://doi.org/10.1016/j.knosys.2008.09.001

[12] Diab, H. B., Demashkieh, I. (1991). A computer-aided teaching package for microprocessor systems education. IEEE Transactions on Education, 34(2): 179-183. https://doi.org/10.1109/13.81598 
[13] Liu, P. L., Chen, C. J., Chang, Y. J. (2010). Effects of a computer-assisted concept mapping learning strategy on efl college students' English reading comprehension. Computers \& Education, 54(2): 436-445. https://doi.org/10.1016/j.compedu.2009.08.027

\section{Author}

Lingling Qiu now works as a lecturer in Guizhou University of Finance and Economics, taking courses of College English on Reading and Listening and so on. The students of hers has won the first prize in Provincial English Speech Contest and the second or third prize in Provincial English Writing Contest and other national prizes as well. She used to work as an interpreter for provincial governor of Guizhou as well as other government officials in meeting with foreign delegations.

Article submitted 2019-05-19. Resubmitted 2019-07-03. Final acceptance 2019-07-03. Final version published as submitted by the authors. 